\title{
Surgery in South Africa - the attitudes toward mentorship in facilitating general surgical training
}

\author{
P Naidu, ${ }^{1}$ (D) I Buccimazza ${ }^{2}$ iD \\ ${ }^{1}$ Department of Surgery, Faculty of Health Sciences, University of Cape Town, South Africa \\ ${ }^{2}$ Department of Surgery, Inkosi Albert Luthuli Hospital, KwaZulu-Natal Department of Health, South Africa
}

Corresponding author, email: pnaidu2012@gmail.com

Background: There are many barriers to pursuing a surgical career in South Africa, some of which are unique to females. Mentorship has been proposed as a solution to mitigate these barriers. The value of mentorship has not been formally assessed among South African general surgeons and trainees.

Methods: The study was part of a larger study designed to assess barriers to pursuing a career in surgery, including the value of mentorship. A 15 -item questionnaire was designed and distributed via the Research Electronic Database Capture from 1 February 2020-3 April 2020. Data were analysed using Stata 15 SE. All responses were anonymised.

Results: One hundred and twenty-nine (13.5\%) of 955 potential participants responded to the survey of which $26 \%$ (33/129) were female. Sixty-seven per cent of respondents were specialist surgeons (87/129). Seventy per cent (90/129) of participants reported having a role model in surgery, however, $66 \%(86 / 129)$ reported they had no mentor in surgery. $107 / 129$ (83\%) participants reported the importance of mentorship. The need for a formalised mentorship programme to facilitate surgical training was recorded by $60 \%$ (78/129) of participants, while $18 \%(23 / 129)$ reported the need for a mentorship group specifically for females.

Conclusion: Eighty-three per cent of participants reported the importance of mentorship however two-thirds lacked a mentor. Most participants advocated for a mentorship group to facilitate surgical training. Establishing formalised mentorship programmes could mitigate the barriers to pursuing a surgical career.

Keywords: surgery, training, barriers, mentorship

Appendix 1 available online: http://sajs.redbricklibrary.com/index.php/sajs/article/view/3597

\section{Introduction}

Surgery is a highly competitive specialty and a particularly challenging learning environment. ${ }^{1}$ Barriers to pursuing a career in surgery include heavy workload, poor worklife balance, verbal discouragement, and limited options for postgraduate surgical training. These barriers can lead to low interest to pursue a surgical career choice. Challenges identified in the surgical workplace include, among others, verbal, physical and emotional abuse, long working hours, and lack of time for commitments outside of surgery. ${ }^{1,2}$ Challenges in the surgical workplace have led to burnout, physical and emotional exhaustion, and even attrition of surgeons. Some of these challenges are unique to female surgeons, such as limited time to plan a family and gender discrimination in the workplace. ${ }^{3}$ There is an increasing number of female doctors in medicine, yet a disproportionately low number of women in surgery. In South Africa, $60 \%$ of medical students are female, however, only five per cent are surgeons. ${ }^{4}$ The under-representation of women in surgery is evident at all levels including in academic and leadership positions. ${ }^{5,6}$

Mentorship has been gaining traction in the field of surgery and can be an important way to mitigate challenges of and barriers to pursuing a surgical career. Mentorship has been defined as a "two-way relationship and type of human development in which one individual invests personal knowledge, energy and time in order to help another individual grow and develop and improve to become the best and most successful they can be." Mentors can be important facilitators of the entrance of young doctors, particularly female doctors, into the field of surgery. ${ }^{8}$ Mentors can also play an important role in a mentee's career satisfaction and development, particularly in academia, and aid in the retention of surgeons. ${ }^{9}$

While evaluation of mentorship in surgery has been increasingly reported in the literature from high-income countries, such as the United States, there is a paucity of literature on the value or perceptions of mentorship in lowand middle-income settings, such as South Africa. ${ }^{1,9}$

The primary objective of this survey was to determine the value of mentorship among South African general surgeons. The secondary objectives of this study were to determine the proportion of participants that felt a formalised mentorship programme for surgical trainees in general and women in particular was needed. 


\section{Methods}

This was a cross-sectional survey conducted using a 15item questionnaire (Appendix 1) which was designed and distributed via the Research Electronic Database Capture (REDCap) software (version 8.1.13, Vanderbilt University). The survey was developed by both authors, the senior author being a surgical sub-specialist, and included questions on challenges and barriers to pursuing a career in surgery, as well as the attitudes and perceptions of mentorship in facilitating surgical training. These questions were adapted from previously published studies. ${ }^{1-3,9}$ Questions on the value of mentorship were single-answer choice questions except for the question on methods to facilitate surgical training, where participants were allowed to select multiple answers. The questions on the value of mentorship were analysed using Stata 15 SE. The survey was circulated to qualified general surgeons who are members of the Association of Surgeons South Africa (ASSA) or Surgicom, as well as to general surgical trainees through their heads of department. The survey was conducted over a two-month period from 1 February 2020 to 3 April 2020. All responses were anonymous, and no identifying data were included. Descriptive analysis of the data was performed using measures of dispersion (means and median).

\section{Results}

One hundred and twenty-nine (13.5\%) out of 955 general surgeons and trainees approached to participate, responded to the survey. Seventy-four per cent $(96 / 129)$ were male and $47 \%$ $(60 / 129)$ were older than 50 years of age (Table I). Sixty-seven per cent $(87 / 129)$ of participants were consultant surgeons with a median of 18 years (IQR 10-28) post-fellowship experience. Twenty-three $(18 \%)$ of the participants were registrars in surgical training and the median number of years in training was two years (IQR 1-3).

Fifty-three per cent of participants $(69 / 129)$ reported having a role model in their lives and 70\% (90/129) reported the presence of a role model in surgery (Table II). This role

\begin{tabular}{lc} 
Table I: Demographic characteristics & \\
\hline Characteristics & $n=129$ \\
\hline Gender & $96(74 \%)$ \\
Male & $33(26 \%)$ \\
Female & $n=129$ \\
Age & $8(6 \%)$ \\
$20-29$ & $36(28 \%)$ \\
$30-39$ & $25(19 \%)$ \\
$40-49$ & $60(47 \%)$ \\
$>50$ & $n=129$ \\
Position & $87(67 \%)$ \\
Consultant & $8(6 \%)$ \\
Fellow & $5(4 \%)$ \\
Medical officer in surgery & $23(18 \%)$ \\
Registrar & $6(5 \%)$ \\
Unspecified & $18(10-28)$ \\
Median number of years post-fellowship (IQR) & $2(1-3)$ \\
Median years in registrar training (IQR)
\end{tabular}

Table II: Presence of role models and mentors

\begin{tabular}{|c|c|c|c|}
\hline & $\begin{array}{c}\text { Male } \\
(n=96)\end{array}$ & $\begin{array}{l}\text { Female } \\
(n=\mathbf{3 3})\end{array}$ & $n=129$ \\
\hline \multicolumn{4}{|l|}{ Presence of a role model in life } \\
\hline Yes & 55 & 14 & $69(53 \%)$ \\
\hline No & 31 & 13 & $44(34 \%)$ \\
\hline No response & 10 & 6 & $16(13 \%)$ \\
\hline \multicolumn{4}{|l|}{$\begin{array}{l}\text { Presence of role model in } \\
\text { surgery }\end{array}$} \\
\hline Yes & 65 & 25 & $90(70 \%)$ \\
\hline No & 21 & 2 & $23(18 \%)$ \\
\hline No response & 10 & 6 & $16(12 \%)$ \\
\hline \multicolumn{4}{|l|}{ Who is your role model } \\
\hline Senior colleague & 62 & 16 & $78(60 \%)$ \\
\hline Other (family member/none) & 18 & 5 & $23(18 \%)$ \\
\hline Peer & 6 & 6 & $12(9 \%)$ \\
\hline No response & 10 & 6 & $16(13 \%)$ \\
\hline \multicolumn{4}{|l|}{ Presence of a mentor } \\
\hline Yes & 28 & 15 & $43(33 \%)$ \\
\hline No & 58 & 12 & $70(54 \%)$ \\
\hline No response & 10 & 6 & $16(12 \%)$ \\
\hline Gender of mentor & & & $n=43$ \\
\hline Male & 26 & 10 & $36(84 \%)$ \\
\hline Female & 0 & 2 & $2(5 \%)$ \\
\hline Both & 2 & 3 & $5(12 \%)$ \\
\hline $\begin{array}{l}\text { Number of mentors per } \\
\text { respondent }\end{array}$ & & & $n=43$ \\
\hline 1 & 11 & 3 & $14(32 \%)$ \\
\hline 2 & 9 & 8 & $17(40 \%)$ \\
\hline 3 or more & 8 & 4 & $12(28 \%)$ \\
\hline Presence of a mentee & & & $n=129$ \\
\hline Yes & 42 & 15 & $57(44 \%)$ \\
\hline No & 44 & 12 & $56(43 \%)$ \\
\hline No response & 10 & 6 & $16(13 \%)$ \\
\hline Gender of mentee & & & $n=57$ \\
\hline Male & 16 & 3 & $19(33 \%)$ \\
\hline Female & 2 & 4 & $6(11 \%)$ \\
\hline Both & 24 & 8 & $32(56 \%)$ \\
\hline
\end{tabular}

model in surgery was a senior colleague in $60 \%(78 / 129)$ of cases.

Fifty-four per cent (70/129) did not have a mentor; of these $61 \%(43 / 70)$ felt they lacked mentorship and would have liked to have had a mentor for their career development. Eighty-four per cent (36/43) of the mentees had a male mentor and 68\% (29/43) had two or more mentors. Fortyfour per cent $(57 / 129)$ reported having a mentee with $56 \%$ $(32 / 57)$ having both male and female mentees.

Eighty-three per cent of the participants (107/129) reported that they felt it was important to have a mentor (Table III). 


\begin{tabular}{|c|c|c|c|}
\hline & Male & Female & Total \\
\hline Important to have a mentor? & & & $n=129$ \\
\hline Yes & 82 & 25 & $107(83 \%)$ \\
\hline No & 3 & 2 & $5(4 \%)$ \\
\hline Missing & 11 & 6 & $17(13 \%)$ \\
\hline $\begin{array}{l}\text { Perceived lack of mentorship (if } \\
\text { no mentor) }\end{array}$ & & & $n=70$ \\
\hline Yes & 30 & 13 & $43(61 \%)$ \\
\hline No & 14 & 13 & $27(39 \%)$ \\
\hline Facilitation of surgical training & & & $n=129$ \\
\hline Mentorship programme & 57 & 19 & $76(59 \%)$ \\
\hline $\begin{array}{l}\text { Postgraduate surgical } \\
\text { training scholarships }\end{array}$ & 50 & 11 & $61(47 \%)$ \\
\hline $\begin{array}{l}\text { Part-time surgical training } \\
\text { programmes }\end{array}$ & 36 & 10 & $46(36 \%)$ \\
\hline $\begin{array}{l}\text { Other (flexible training } \\
\text { programmes, appropriate } \\
\text { cover of maternity leave, } \\
\text { part-time post graduate } \\
\text { training, better working } \\
\text { hours) }\end{array}$ & 15 & 2 & $17(13 \%)$ \\
\hline $\begin{array}{l}\text { Is there a need for a mentorship } \\
\text { group for all surgeons? }\end{array}$ & & & $n=129$ \\
\hline Yes & 56 & 22 & $78(60 \%)$ \\
\hline No & 6 & 4 & $10(8 \%)$ \\
\hline Unsure & 34 & 7 & $41(32 \%)$ \\
\hline $\begin{array}{l}\text { Is there a need for a group to } \\
\text { support female surgeons? }\end{array}$ & & & $n=129$ \\
\hline Yes & 7 & 16 & $23(18 \%)$ \\
\hline No & 20 & 7 & $27(21 \%)$ \\
\hline Unsure & 50 & 3 & $53(41 \%)$ \\
\hline Missing & 18 & 8 & $26(20 \%)$ \\
\hline
\end{tabular}

The need for a formal mentorship group for all surgeons was recommended by $60 \%(78 / 129)$ of the participants, whereas $18 \%(23 / 129)$ reported the need for a group to specifically support female surgeons; 16 out of the $23(70 \%)$ respondents were female.

\section{Discussion}

Our survey shows that South African general surgeons and trainees perceive the need for mentorship in surgery. Eightythree per cent of participants regarded the presence of a mentor as important, yet two-thirds did not have a mentor in surgery. Sixty per cent of participants reported that a mentorship programme would facilitate surgical training and a similar amount further reported the need for a formalised mentorship group for all surgeons.

Mentors can play a role in aiding retention of surgeons and increasing career satisfaction by creating a supportive environment that cultivates learning, advice on how to mitigate stress and decrease barriers to pursuing surgical careers, particularly for female doctors. ${ }^{10}$ Surgical trainees in orthopaedics who had mentors reported significantly higher job satisfaction and career development than those without mentors. ${ }^{11}$ There are several barriers to effective mentorship which include time constraints, generational and cultural differences, scarcity of qualified mentors and gender differences. ${ }^{8}$ While mentorship has often been regarded as a casual relationship, recent literature argues that mentorship should be cultivated in surgical programmes as this is an important method of teaching both technical and nontechnical skills. ${ }^{8,12}$ Formalised mentorship programmes are becoming increasingly important globally for their ability to address mentor time constraints, increase confidence and interest in surgical careers among medical students, ${ }^{13}$ and increase satisfaction of the mentorship environment among surgical trainees. ${ }^{11}$ A recent study in the United Kingdom reported that $83 \%$ of participants (surgeons in various surgical specialties) were willing to undergo formal mentorship training to increase the number of qualified mentors and improve effective mentorship. ${ }^{14}$ However, formalised mentorship programmes require involvement of the surgical department and the academic institution to ensure success. ${ }^{9}$

Numerous organisations, including the College of Surgeons of East, Central, and Southern Africa, have established formalised mentorship groups specifically for female surgeons in all specialties. ${ }^{15}$ These dedicated groups for women in surgery have helped to improve retention of female surgeons in the field by increasing academic and leadership opportunities and providing support for challenges that are unique to female surgeons. ${ }^{15,16}$ A 2017 study reported that same-sex mentorship was preferred among females and could positively influence career choice and address barriers to pursuing surgery, advocating for the development of national mentorship programmes in the United States. ${ }^{17}$ Our study showed that $45 \%$ of female participants had a mentor, and an overwhelming majority ( $84 \%)$ of mentors were male, which could be explained by the male-dominated nature of surgery in South Africa but also suggests a lack of female mentors.

Nearly two-thirds of participants in the current study reported the need for a mentorship group for all surgeons and $70 \%$ of female respondents reported the need for a dedicated group to support female surgeons. Despite this, there is no published data as to whether South African academic institutions have formal mentorship programmes in general or for females specifically and if they are effective. Even in institutions that have established these programmes, there is no data on their effectiveness. We believe it should be a priority to establish formalised mentorship programmes in surgical training programmes whilst at the same time devising metrics to assess their value.

It is recognised that there are several inherent limitations and challenges associated with surveys. There was a relatively low response rate, and the study sample was not representative of all regions and academic institutions in South Africa despite constant communication and reminders to encourage survey completion. Being embedded in a larger questionnaire meant that for simplicity of completion mostly single-answer responses were used. As a result, we were unable to do a more qualitative assessment of some responses; for example, reasons why respondents felt it is important to have a mentor or what aspects the respondents felt they lacked in their training that could be improved by being mentored.

\section{Conclusion}

Despite these limitations, over $80 \%$ of the South African general surgeons and surgical trainees who participated in 
the study valued mentorship and $60 \%$ felt there was a need for a formal mentorship programme to facilitate surgical training.

\section{Conflict of interest}

The authors declare no conflict of interest.

\section{Funding source}

No funding was required.

\section{Disclaimer}

This survey was initiated by and conducted under the auspices of the Association of Surgeons of South Africa (ASSA).

\section{Ethical approval}

Ethical approval for this study was obtained from the University of KwaZulu-Natal Biomedical Research Ethics Committee (protocol number: BREC/00002259/2020).

\section{ORCID}

P Naidu (iD) https://orcid.org/0000-0002-1112-9606

I Buccimazza (iD https://orcid.org/0000-0002-5399-3101

\section{REFERENCES}

1. Mahoney ST, Strassle PD, Schroen AT, et al. Survey of the US surgeon workforce - practice characteristics, job satisfaction, and reasons for leaving surgery. J Am Coll Surg. 2020;230(3):283-93.e1.

2. Hu Y-Y, Ellis RJ, Hewitt DB, et al. Discrimination, abuse, harassment, and burnout in surgical residency training. $\mathrm{N}$ Engl J Med. 2019;381(18):1741-52.

3. Roodt L. Female general surgeons - current status, perceptions and challenges in South Africa. A pilot study at a single academic complex. University of Cape Town; 2016.

4. Boffard K. SA trauma expert to head world body. S Afr Med J. 2010;100:144-5.
5. Cochran A, Elder WB, Crandall M, et al. Barriers to advancement in academic surgery - views of senior residents and early career faculty. Am J Surg. 2013;206(5):661-6.

6. Cochran A, Hauschild T, Elder WB, et al. Perceived genderbased barriers to careers in academic surgery. Am J Surg. 2013;206(2):263-8.

7. Flaherty J. Coaching - evoking excellence in others. 2nd ed. Development and Learning in Organizations. Taylor \& Francis Ltd; 2006.

8. Entezami P, Franzblau LE, Chung KC. Mentorship in surgical training - a systematic review. Hand. 2012;7(1):30-6.

9. Kibbe MR, Pellegrini CA, Townsend CM, Helenowski IB, Patti MG. Characterisation of mentorship programmes in departments of surgery in the United States. JAMA Surg. 2016;151(10):900-6.

10. Welch JL, Jimenez HL, Walthall J, Allen SE. The women in emergency medicine mentoring programme - an innovative approach to mentoring. J Grad Med Educ. 2012;4(3):362.

11. Flint JH, Jahangir AA, Browner BD, Mehta S. The value of mentorship in orthopaedic surgery resident education - the residents' perspective. JBJS. 2009;91(4):1017-22.

12. Holt GR. Idealised mentoring and role modeling in facial plastic and reconstructive surgery training. Arch Facial Plast Surg. 2008;10(6):421-6.

13. Drolet BC, Sangisetty S, Mulvaney PM, Ryder BA, Cioffi WG. A mentorship-based preclinical elective increases exposure, confidence, and interest in surgery. Am J Surg. 2014;207(2):179-86.

14. Sinclair P, Fitzgerald J, Hornby S, Shalhoub J. Mentorship in surgical training - current status and a needs assessment for future mentoring programmes in surgery. World J Surg. 2015;39(2):303-13.

15. McCarthy MC. The Association of Women Surgeons - a historical perspective 1981 to 1992. Arch Surg. 1993;128(6):633-6.

16. Odera A, Tierney S, Mangaoang D, Mugwe R, Sanfey $\mathrm{H}$. Women in surgery Africa and research. Lancet. 2019;393(10186):2120.

17. Faucett EA, McCrary HC, Milinic T, et al. The role of samesex mentorship and organisational support in encouraging women to pursue surgery. Am J Surg. 2017;214(4):640-4. 